\title{
Targeted and Untargeted Metabolite Profiling of the Ethnobotanical Martynia annua L. Identifies Bioactive Compounds with Medicinal Properties
}

\section{(요 $(3 \Theta$}

Authors

Saba Muazzam ${ }^{1,2}$, Joe Harvey², Thibaut Deviese ${ }^{3}$, Muhammad Farman', James McCullagh²

\section{Affiliations}

1 Department of Chemistry, Quaid-i-Azam University, Islamabad, Pakistan

2 Chemistry Research Laboratory, Department of Chemistry, University of Oxford, Oxford, United Kingdom

3 Research Laboratory for Archaeology and the History of Art, University of Oxford, Oxford, United Kingdom

Key words

Martynia annua, Martyniaceae, LC-MS/MS, plant secondary metabolites, polyphenols, metabolic profiling, ethnomedicine

received $\quad 09.07 .2018$

revised 28.08.2018

accepted 23.09.2018

\section{Bibliography \\ DOI https://doi.org/10.1055/a-0754-5916 \\ Planta Med Int Open 2018; 5: e68-e78 \\ (c) Georg Thieme Verlag KG Stuttgart - New York \\ ISSN 2509-9264}

\section{Correspondence}

Prof. Dr. James McCullagh

Chemistry Research Laboratory

Department of Chemistry

University of Oxford

Mansfield Road

Oxford

OX1 3TA

United Kingdom

Tel.: +44/1865/275657, Fax: +44/1865/285002

james.mccullagh@chem.ox.ac.uk
Supporting Information for this article is available online at
http://www.thieme-connect.de/products

\section{ABSTRACT}

Martynia annua is an indigenous plant found endemic in the Indian subcontinent where it is commonly used for self-treatment of a variety of ailments and diseases. Previous studies have shown that preparations from the plant have antiseptic, anti-inflammatory, and antiepileptic effects in vitro, but the biochemical composition and active compounds responsible for health benefits remain unknown. The aim of this study was to take extracts from different parts of the M. annua plant and, using targeted and untargeted metabolite profiling and quantitation, provide a comprehensive secondary metabolite profile to identify potential biotherapeutic metabolites.

Ultrahigh-performance liquid chromatography, coupled directly to a Thermo Q-Exactive Orbitrap mass spectrometer, was used for high-resolution targeted and untargeted analysis. 89 metabolites were identified and their relative and selected absolute abundances measured across 5 different parts of the plant (leaf, flower, fruit, stem, and root). A number of the compounds identified are known to have bioactive and therapeutic properties; these include trans-ferulic acid, homovanillic acid, syringic acid, isorhamnetin, apigenin, luteolin, and hispidulin. We report their concentrations in different parts of the plant. Our findings significantly extend the plant metabolite profile of $\mathrm{M}$. annua and amongst the compounds identified, we have highlight those with known biotherapeutic properties. These results provide a foundation for future studies addressing specific compounds that may be responsible for the bioactivity and therapeutic use of M. annua.

\section{Introduction}

Martynia annua L. (Martyniaceae) is native to Mexico and is also found throughout India and Pakistan where it is commonly known by various names, including “cat's claw”, “devil's claw”, "bichchhu”, "pulinagam” [1], "kakanasika”, and “vichchida” [2]. It is a herbaceous erect, branched, glandular-hairy, annual herb growing to 0.9-1.2 m in height and is found in wastelands, rubbish heaps, and on roadsides [3]. Various parts of the plant are used for self-treatment of a number of ailments in multiple prepared forms. The leaves have been shown to have anti-convulsion activity against animal models [4]. The juice of the leaves is used as a gargle for sore throats and the leaf 
paste for wounds of domestic animals [5]. The fruits are used as a local sedative and also as an antidote to scorpion stings and other venomous bites and stings [6]. The species is known to contain a broad spectrum of medicinally useful compound classes, mainly tannins, alkaloids, various glycosides, carbohydrates, anthocyanins [7], and flavonoids [8], that are associated with bioactivity, including antioxidant, antibacterial, analgesic, antipyretic, anthelmintic, and anticonvulsant [3]. However, to date, a broad individual compound profile from the plant has not been published using untargeted analytical approaches.

Polyphenols have garnered considerable interest because of their potential beneficial antioxidant and biochemical effects $[9,10]$. In plants, they often occur as the aglycone form or are glycosylated with a range of sugar moieties that help their solubility and transport in the plant. However, during the course of digestions and absorption by humans and animals, polyphenols almost always undergo multiple chemical modifications. The most common dietary polyphenols absorbed are therefore not necessarily those with the highest concentration or the greatest bioactivity in vitro. This has made studying the specific health benefits of different types of polyphenols and in whole plants a challenge [11]. Indeed, the situation is complicated because modification of polyphenols during absorption is often dependent on the composition of gut microflora in humans and animals, which can differ significantly between individuals and species and can mediate the potency of subsequent biological effects [12]. Nevertheless, a number of pharmacological and epidemiological studies have shown that the intake of flavonoids is commensurate with subsequent health benefits, including antioxidant activity [13], antiviral activity [14], antitumor activity [15], anti-inflammatory activity [16], hepatoprotective activity [17], and the prevention of cardiovascular diseases [18].

Despite the purported health benefits of M. annua, very few systematic studies have been conducted to investigate compounds from this plant that may be responsible for therapeutic benefits. The objectives of this study were therefore to (1) use untargeted metabolic profiling to provide a broad metabolite profile, and to investigate and compare extracts from different parts of the plant, namely, leaves, roots, stem, flowers, and fruit, (2) to provide an absolute quantitative measure of abundance for selected identified metabolites where possible, and (3) to identify selected natural products with known therapeutic properties.

\section{Results and Discussion}

Metabolic profiling was performed on solvent extracts from the leaves, flowers, fruits, stem, and roots of the M. annua plant. Each extract was analysed using ultra-performance chromatography coupled to high-resolution mass spectrometry using a modified version of the method published by Want and coworkers [19]. We validated the modified protocol by establishing limits of detection (LOD), limits of quantification (LOQ), linearity via the construction of calibration curves, method selectivity, and reproducibility ( $\triangleright$ Table 1S and $\triangleright$ Fig. 1S, Supporting Information).

In order to determine an optimal metabolite extraction protocol for each of the plant parts, 3 separate methods were tested: homogenisation, maceration, and ultrasonication (see experimental section). Extracts, using the 3 methods, were generated and then compared by LC-MS/MS. - Fig. 1 provides principal components analysis (PCA) for the abundances of all measured ion features (representing compounds in the sample) for each extraction method (A-C) and combined methods data (D). The 3 points for each plant part represent 3 independent extractions from the same starting material. The difference in the reproducibility of each method, represented by all measured compounds, can be estimated by how well the experimental replicates cluster together. The homogenisation method was the most reproducible. - Table 2S, Supporting Information, provides a heat map ranking the average calculated concentration for each of the identified metabolites from the leaf extracts (see next section). Red $=$ most abundant, green $=$ median abundance, and blue = least abundant. The maceration method provided higher ion abundances, but given its significantly greater reproducibility and average extraction efficiency, the homogenisation method was used to conduct all subsequent plant extractions in this study.

Having validated the analytical method and sample extraction protocol, we analysed 3 biological replicates from each plant part using the homogenisation extraction method. A total of 7697 unique ion features were recorded with a $\% C V<30$ (representing compounds that were well characterised by the analytical method) across each of the plant extracts. This was commensurate with previous untargeted metabolite profiling of plant extracts [10]. The peak area for each ion feature representing a metabolite was assigned a unique retention time and accurate mass value prior to metabolite identification. $>$ Fig. 2 provides a graph with the number of compounds identified and their distribution across each of the 5 plant extracts. Extracts from the plant's flowers provided the greatest number of different compound features (5121) and those from the stem the least (4403). The majority of compounds features were identified in common across multiple plant parts.

For the identification of metabolites in plant extracts, 101 authentic plant secondary metabolite standards were purchased. Each authentic standard was analysed using the same analytical method used for the plant extracts. The retention time, isotope pattern, directed fragmentation patterns, and accurate mass values were recorded. These experimental values were then compared with those from the LC-MS/MS analyses of the M. annua extracts. A 'level 1' identification was assigned if the following criteria were met $[20,21]$ : an $\mathrm{m} / \mathrm{z}$ value within $5 \mathrm{ppm}$ of the calculated accurate mass that was also within $10 \mathrm{~s}$ of the retention time for the authentic standard and $>95 \%$ similarity between its measured and theoretical isotope pattern. Fragmentation patterns were used as an additional confirmatory match for over $80 \%$ of the identifications but were not available for every compound due to their ion abundance not being isolated via data-directed nature of the LC-MS/MS fragmentation method. $\triangleright$ Table 1 provides a list of the metabolites and the analytical measurements used to identify them.

Next, an external calibration curve for each of the 16 compounds was constructed and used to estimate the concentration of each of the compounds identified in the plant extracts ( $\triangleright$ Fig. 1S and - Table 1S, Supporting Information). The calculated absolute concentrations for each of the identified compounds in each of the plant extracts are shown in $>$ Table 2.

The identity and structures of a further 18 conjugated secondary metabolites were elucidated without the use of authentic 
a

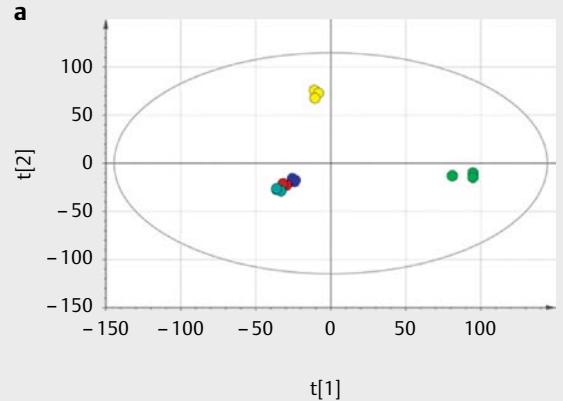

c

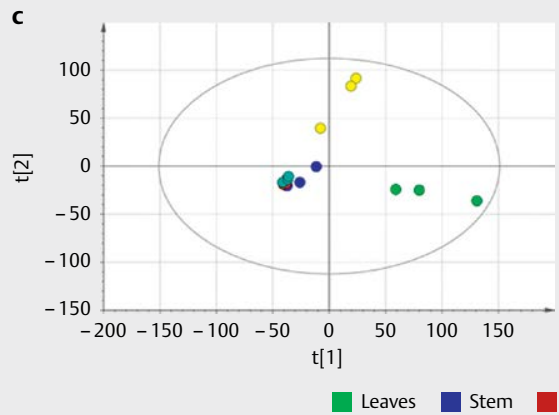

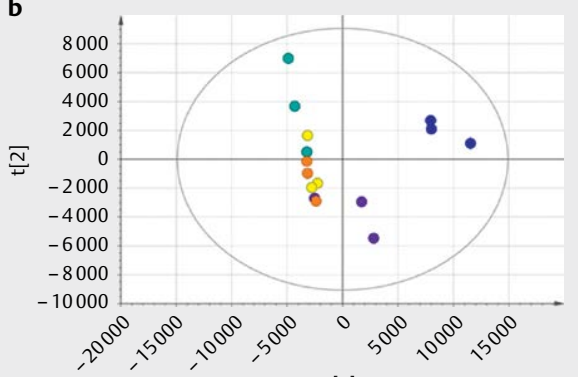

$\mathrm{t}[1]$

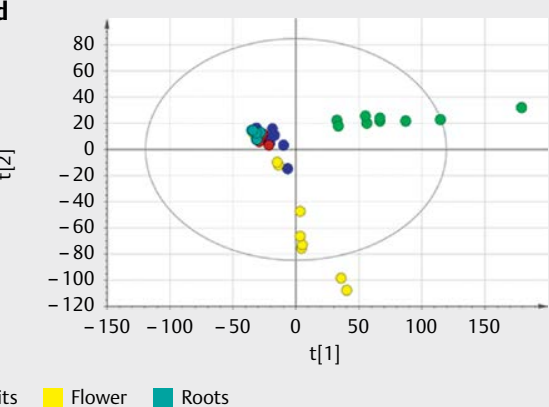

- Fig. 1 Principal components analysis (PCA) shows the relative variability of each extraction method tested. $\mathbf{a}=$ Homogenisation; $\mathbf{b}=$ Sonication; $\mathbf{c}=$ Maceration. The homogenisation method demonstrated the most consistent results between experimental replicates ( $n=3$ for each method.) $\mathbf{d}=$ All extraction methods combined. The plots also demonstrate visually that total chemical composition variability between plant parts is greatest between leaves and flowers compared to other parts of the plant. Stem, roots, and, interestingly the fruit tend to be closer to each other in their small molecule composition.

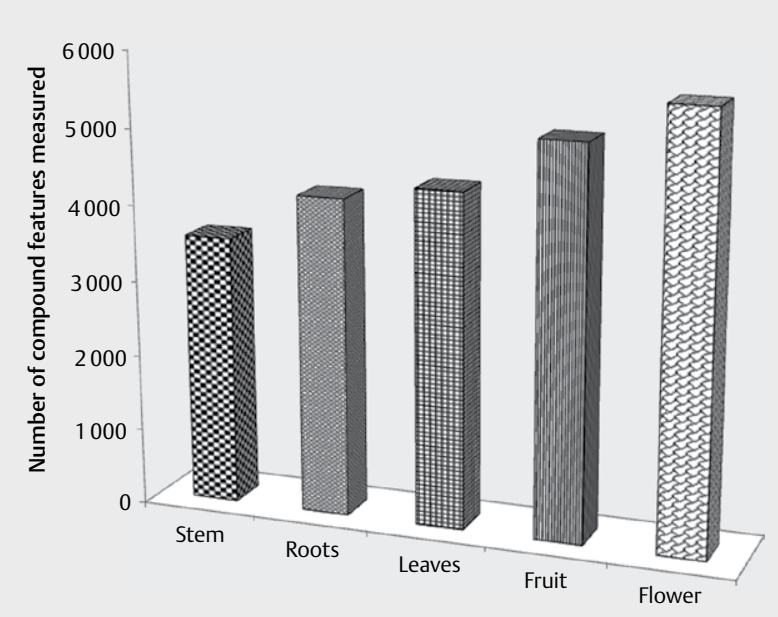

- Fig. 2 The number of individual compound features measured in each of the 5 different plant part extracts from M. annua. Analysis by LC-MS/MS.

standards by a combination of accurate mass, isotopic pattern matching, and detailed comparison with published MS fragmentation data [22-25]. The following section provides a detailed description of the assignments which reflect the fact that their conjugated forms lead to a characteristic loss of glycoside sugar moieties. These were assigned 'level 2' identifications and are presented in $>$ Table 3.
Detection of the deprotonated molecules was coupled with MS2 fragmentation using a data-directed (DDA) HCD fragmentation method (see experimental section). Accurate masses, isotope abundances, and fragmentation patterns were measured for compounds meeting the DDA criteria in the analysis of each sample. Using these criteria to match against the theoretical values obtained from chemical formulae and structures of a much larger number of polyphenols found in the scientific literature, further putative identifications were made. Fragmentation of conjugated species often revealed carbohydrate and aglycone fragments, making it relatively straightforward to identify constituents of the molecule.

Flavonoid aglycones are a structurally diverse group due to the variations that occur at the level of oxygenation (hydroxyl or methoxyl groups) and the point of attachment of ring $B$ (flavonoids and isoflavonoids). From the tandem mass spectra of flavonoid glycosides the accurate mass of selected fragments including the aglycone was measured (pattern of hydroxylation on the aglycone, point of attachment of ring $B$ and ring $C$ ) and it was also often possible to determine information about acylation of sugar hydroxyl groups, possible methylation or sulphation of aglycone hydroxyl(s), number of sugar rings, and, in some cases, placement of glycosidic bonds [26].

Flavonoids occur as flavonoid -O and - $\mathrm{C}$ glycosides, but are more commonly -O glycosides, in which one or more-OH groups of the aglycone are linked to a sugar moiety (commonly, glucose, galactose, rhamnose, xylose) with the formation of an acid-labile hemiacetal bond known as a glycosidic $(\mathrm{O}-\mathrm{C})$ bond. The $-\mathrm{OH}$ groups of 
- Table 1 The 16 plant secondary metabolites and associated analytical data of identified compounds from M. annua.

\begin{tabular}{|c|c|c|c|c|c|c|c|c|}
\hline No & Compound ID & RT (min) & $\begin{array}{l}\text { Rt error } \\
\text { (min) }\end{array}$ & {$[\mathrm{M}-\mathrm{H}]^{-}$} & $\begin{array}{l}\text { Mass error } \\
(\mathrm{ppm})\end{array}$ & $\begin{array}{l}\text { Isotope pattern } \\
\text { similarity (\%) }\end{array}$ & $\begin{array}{l}\text { Fragmentation } \\
\text { score (\%) }\end{array}$ & $\begin{array}{c}\text { Compound ID } \\
\text { level }^{*}\end{array}$ \\
\hline 1 & Protocatechuic acid & 2.10 & -0.11 & 153.0193 & -0.1 & 98 & 91.8 & 1 \\
\hline 2 & Gentisic acid & 3.21 & -0.04 & 153.0193 & 0.1 & 98 & 80.1 & 1 \\
\hline 3 & Caffeic acid & 3.54 & 0.01 & 179.0346 & $\begin{array}{ll}-1.6 \\
\end{array}$ & 97 & 93 & 1 \\
\hline 4 & Syringic acid & 3.66 & -0.01 & 197.0454 & -0.6 & 95 & 0 & 1 \\
\hline 5 & Rutin & 3.97 & 0.02 & 609.1457 & -0.5 & 0 & 87.9 & 1 \\
\hline 6 & Homovanilic acid & 4.00 & 0.32 & 181.0504 & -0.8 & 96 & 0 & 1 \\
\hline 7 & p-Coumaric acid & 4.01 & -0.03 & 163.0399 & -0.5 & 97 & 96.6 & 1 \\
\hline 8 & Sinapic acid & 4.23 & 0.00 & 223.0612 & 0.1 & 0 & 65 & 1 \\
\hline 9 & trans-Ferulic acid & 4.23 & -0.02 & 193.0504 & 1.8 & 99 & 99.3 & 1 \\
\hline 10 & Salicylic acid & 4.83 & 0.07 & 137.0423 & -0.4 & 94 & 0 & 1 \\
\hline 11 & Luteolin & 5.07 & -0.02 & 285.0410 & 2.1 & 99 & 81.7 & 1 \\
\hline 12 & Apigenin & 5.50 & -0.04 & 269.0457 & 0.6 & 97 & 48.8 & 1 \\
\hline 13 & Kaempferol & 5.58 & -0.01 & 285.0410 & 2.1 & 99 & 55.0 & 1 \\
\hline 14 & Hispidulin & 5.62 & 0.01 & 299.0567 & 2.0 & 97 & 98.8 & 1 \\
\hline 15 & Hesperetin & 5.67 & -0.01 & 301.0723 & 2.0 & 98 & 75.7 & 1 \\
\hline 16 & Isorhamnetin & 5.68 & -0.01 & 315.0515 & 1.6 & 94 & 78.5 & 1 \\
\hline
\end{tabular}

- Table 2 Absolute concentrations of identified compounds across each plant part (ng/g plant material).

\begin{tabular}{|c|c|c|c|c|c|c|}
\hline \multirow[t]{2}{*}{ No } & \multirow[t]{2}{*}{ Identified compounds } & \multicolumn{5}{|c|}{ Minimum concentrations ( $\mathrm{ng} / \mathrm{g}$ of plant material) } \\
\hline & & Leaves & Stem & Fruit & Flower & Root \\
\hline 1 & Protocatechuic acid & 38 & 33 & 32 & 56 & 26 \\
\hline 2 & Gentisic acid & 11 & 4 & 4 & 4 & 6 \\
\hline 3 & Caffeic acid & 154 & 153 & 141 & 145 & 138 \\
\hline 4 & Syringic acid & 757 & 714 & 715 & 718 & 712 \\
\hline 5 & Rutin & 41 & 13 & - & 761 & - \\
\hline 6 & Homovanilic acid & 608 & 597 & 593 & 664 & 567 \\
\hline 7 & p-Coumaric acid & 11 & 2 & - & 1 & - \\
\hline 8 & Sinapic acid & 168 & 177 & 174 & 170 & 172 \\
\hline 9 & trans-Ferulic acid & 34118 & 43252 & 36100 & 36298 & 53288 \\
\hline 10 & Salicylic acid & 39 & 15 & 16 & 28 & 23 \\
\hline 11 & Luteolin & 60 & - & 35 & 492 & - \\
\hline 12 & Apigenin & 239 & 6 & 110 & 682 & 7 \\
\hline 13 & Kaempferol & 5 & - & - & - & - \\
\hline 14 & Hispidulin & 169 & 40 & 91 & 1017 & 7 \\
\hline 15 & Hesperetin & 22 & 21 & 21 & 25 & - \\
\hline 16 & Isorhamnetin & 6837 & - & - & 263 & - \\
\hline
\end{tabular}

flavonoids can be glycosylated but certain positions are favoured, e. g., the 7-OH group in flavones, isoflavones, and flavanones. In flavonol and flavanols, the 3- and 7-hydroxyl groups and the 3-and 5-OH in anthocyanidins are the most common glycosylation sites. Acylated glycosides are also found in nature, in which one or more of the sugar -OH groups are esterified with an acid. Disaccharides like neohesperidose (rhamnosyl-[1 $\rightarrow 2]$-glucose) and rutinose (rhamnosyl-[1 $\rightarrow 6]$-glucose) are also found in association with flavonoids, and occasionally tri- and even tetrasaccharides also occur [27]. Precursor ions could exist in a number of different adducts forms. For simplicity, the compounds identified and shown in - Table 3 were all represented by $[\mathrm{M}-\mathrm{H}]^{-}$precursor ions. A description of how mass spectral and tandem mass spectral measurements were used to propose the identity of each compound in > Table 3 is given in Supporting Information.

Finally, the measured accurate mass value, measured isotope pattern, and tandem mass spectra for each metabolite were compared with those from the human metabolome database (HMDB). The HMDB is an online structural database with over 75000 compounds that have been found in human samples, from both endog- 
- Table 3 Mass spectral identification of phenolic acid and flavonoid glycosides.

\begin{tabular}{|c|c|c|c|c|c|c|c|c|}
\hline No & Compound ID & $\begin{array}{l}\text { RT } \\
(\min )\end{array}$ & {$[\mathrm{M}-\mathrm{H}]^{-}$} & $\begin{array}{l}\text { Mass error } \\
(\mathrm{ppm})\end{array}$ & $\begin{array}{l}\text { Base peak } \\
(m / z)\end{array}$ & $\begin{array}{l}\text { Isotopic } \\
\text { similarity (\%) }\end{array}$ & Mass fragments & $\begin{array}{l}\text { ID } \\
\text { Level }\end{array}$ \\
\hline 17 & $\begin{array}{l}\text { 4-Hydroxybenzoic acid 4-O-gluco- } \\
\text { side }\end{array}$ & 0.68 & 299.0780 & 2.5 & 137.0243 & 96 & {$[\mathrm{M}-\mathrm{H}-\text { glucose }]^{-}$} & 2 \\
\hline 18 & Cinnamoyl glucose & 0.79 & 309.0990 & 3.1 & 89.0243 & 93 & $\begin{array}{l}\text { [M-H-glucose-acetic } \\
\text { acid radical] }{ }^{-}\end{array}$ & 2 \\
\hline 19 & Ferulic acid 4-O-glucoside & 3.11 & 355.1051 & 4.5 & 193.0506 & 96 & {$[\mathrm{M}-\mathrm{H} \text {-glucose }]^{-}$} & 2 \\
\hline 20 & Luteolin-7-O-rutinoside & 3.24 & 593.1507 & -0.7 & 284.0337 & 89 & [M-H-rutinose]- & 2 \\
\hline 21 & p-Coumaric acid-4-O-glucoside & 3.28 & 325.0941 & 3.6 & 163.0399 & 95 & {$[\mathrm{M}-\mathrm{H} \text {-glucose }]^{-}$} & 2 \\
\hline 22 & Hispidulin-7-O-rutinoside & 3.95 & 609.1458 & -0.5 & 300.0284 & 95 & ${\text { [M-H-rutinose }]^{-}}^{-}$ & 2 \\
\hline 23 & Luteolin 7-O-(2-apiosyl-glucoside) & 4.02 & 579.1348 & -1.2 & 284.0333 & 95 & ${\text { [M-H-glucose-xylose }]^{-}}^{-}$ & 2 \\
\hline 24 & Verbascoside & 4.02 & 623.1975 & -1.0 & 161.0243 & 99 & $\begin{array}{l}\text { [M-H-glucose-rham- } \\
\text { nose-hydroxytyrosol] }\end{array}$ & 2 \\
\hline 25 & Quercetin-3-O-glucuronide & 4.10 & 477.0696 & 4.3 & 301.0365 & 96 & [M-H-glucuronic acid] $^{-}$ & 2 \\
\hline 26 & Isorhamnetin-3-O-glucoside & 4.12 & 477.1059 & 4.2 & 315.0522 & 92 & {$[\mathrm{M}-\mathrm{H} \text {-glucose }]^{-}$} & 2 \\
\hline 27 & Isorhamnetin-3-O-glucuronide & 4.13 & 491.0856 & 4.9 & 315.0524 & 95 & 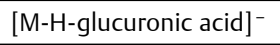 & 2 \\
\hline 28 & Caffeic acid 4-O-glucoside & 4.27 & 341.0891 & 3.8 & 164.0475 & 95 & 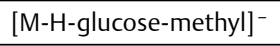 & 2 \\
\hline 29 & Apigenin-7-O-glucuronide & 4.36 & 445.0761 & -3.4 & 269.0455 & 89 & 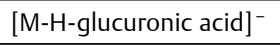 & 2 \\
\hline 30 & Scutellarien & 4.42 & 285.0409 & 1.6 & 285.0409 & 99 & {$[\mathrm{M}-\mathrm{H}]^{-}$} & 2 \\
\hline 31 & p-Coumaroyl glycolic acid & 4.67 & 221.0456 & 0.2 & 159.0811 & 95 & 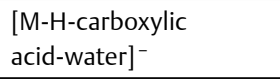 & 2 \\
\hline 32 & Kaempferol-3-O-acetyl-glucoside & 4.99 & 489.1061 & 4.6 & 474.0824 & 95 & [M-H-methyl] $^{-}$ & 2 \\
\hline 33 & 3,7-Dimethylquercetin & 5.67 & 329.0679 & 3.7 & 314.0442 & 98 & [M-H-methyl] $^{-}$ & 2 \\
\hline 34 & Cirsilineol & 6.47 & 343.0838 & 4.1 & 328.0597 & 95 & [M-H-methyl] ${ }^{-}$ & 2 \\
\hline
\end{tabular}

enous and exogenous origins. It therefore contains, and is a useful source of, plant-derived compounds. We identified 55 additional compounds that met the combined criteria: 5 ppm or less mass accuracy, >90\% isotope pattern similarity, and a match between experimental and theoretical tandem mass spectra. A putative identification was assigned only when at least the base peak and an additional "high abundance" peak in the tandem mass spectra (that was not the $[\mathrm{M}-\mathrm{H}]^{-}$peak) were present with less than 5 ppm mass accuracy. These were classed as 'level 2' putative identifications and are listed in $>$ Table 4 . It should be noted that based on accurate mass values, isotope pattern, and some fragmentation matching alone, it is not possible to be certain that all structural isomers are distinguished, particularly those not present in the HMDB database. Hence some "accepted descriptions" in > Table 4 may not be correct, hence their "putative identification" status. However, all 34 level 1 and level 2 identifications found in $>$ Table 1, 3 were also identified using the HMDB search, which provides some confidence in the ability of the HMDB search to correctly identify plantderived metabolites. These have been excluded from $>$ Table 4 so as not to recapitulate data. A total of 89 compounds (composed of level 1 and level 2 assignments) were identified from the $M$. annua plant extracts.

5 of the most abundant compounds identified using authentic standards (trans-ferulic acid, syringic acid, apigenin, isorhamnetin, and hispidulin) have previously been shown to possess bioactive medicinal properties.

The most abundant identified compound was trans-ferulic acid, which is a constituent of plant cell walls. It has antioxidant properties which have also been shown to have antitumour and proapoptotic ef- fects on cancer cells $[44,60]$. Isorhamnetin was the second most abundant compound identified in leaves. This compound has been shown to have anti-inflammatory activity in vitro as well as being an iNOS protein and mRNA expression inhibitor when tested in macrophages stimulated with lipopolysaccharide (LPS) [55, 59, 61-63]. Syringic acid, the third most abundant compound identified in all plant parts, has been previously shown to have antioxidant, antibacterial, and hepatoprotective activity [34,35]. Apigenin, abundant in leaves and flowers, has potent antibacterial effects [51] and anti-leukaemic activity [52]. It also induces autophagy and has been shown to bind to multiple receptors (adenosine, GABA, and opioids), therefore, it is a multimode agonist with potential therapeutic effects [64-67]. Hispidulin, most abundant in flowers, is a bioactive flavone and has been reported as an effective anti-cancer agent and the strongest ligand of the benzodiazepine (BZD) site of the GABA (A) receptor [68]. - Table 5 provides an overview of known biological/medicinal effects of the compounds identified and quantified in the M. annua plant extracts.

This is the first report to profile and quantify significant numbers of secondary metabolites in the medicinally used $M$. annua plant. It provides identification and relative abundance for 89 level 1 and level 2 compounds across extracts from five separate plant parts. It shows that multiple plant parts contain known biotherapeutic compounds at significantly differing concentrations. This study expands the known secondary metabolite constituents of M. annua, shows their relative and absolute abundances in different parts of the plant, and identifies a number of compounds that are known to provide therapeutic effects in vivo. 


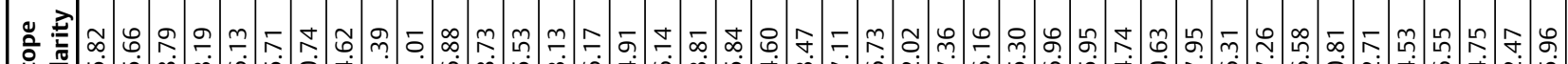
言

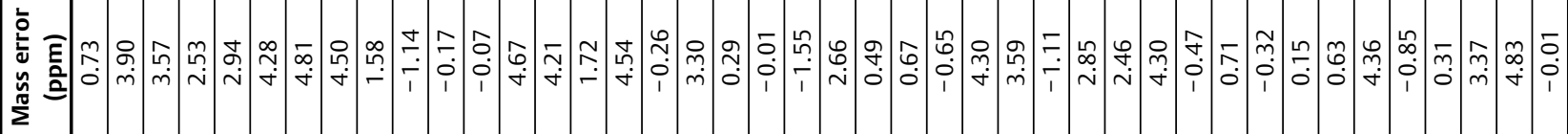

든

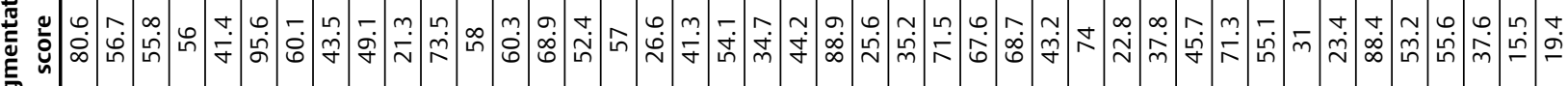

昰

茪 E ᄂ

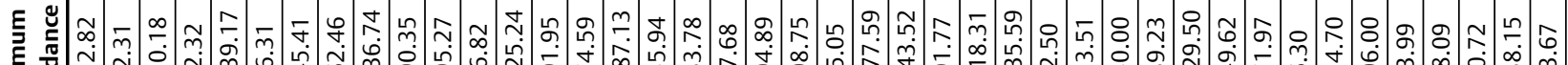

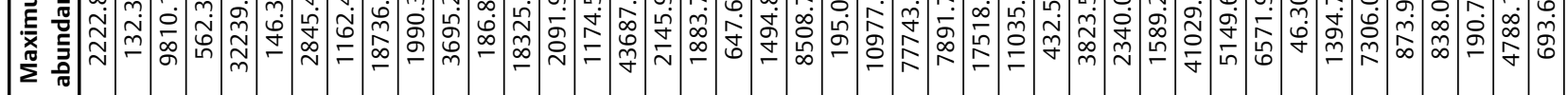

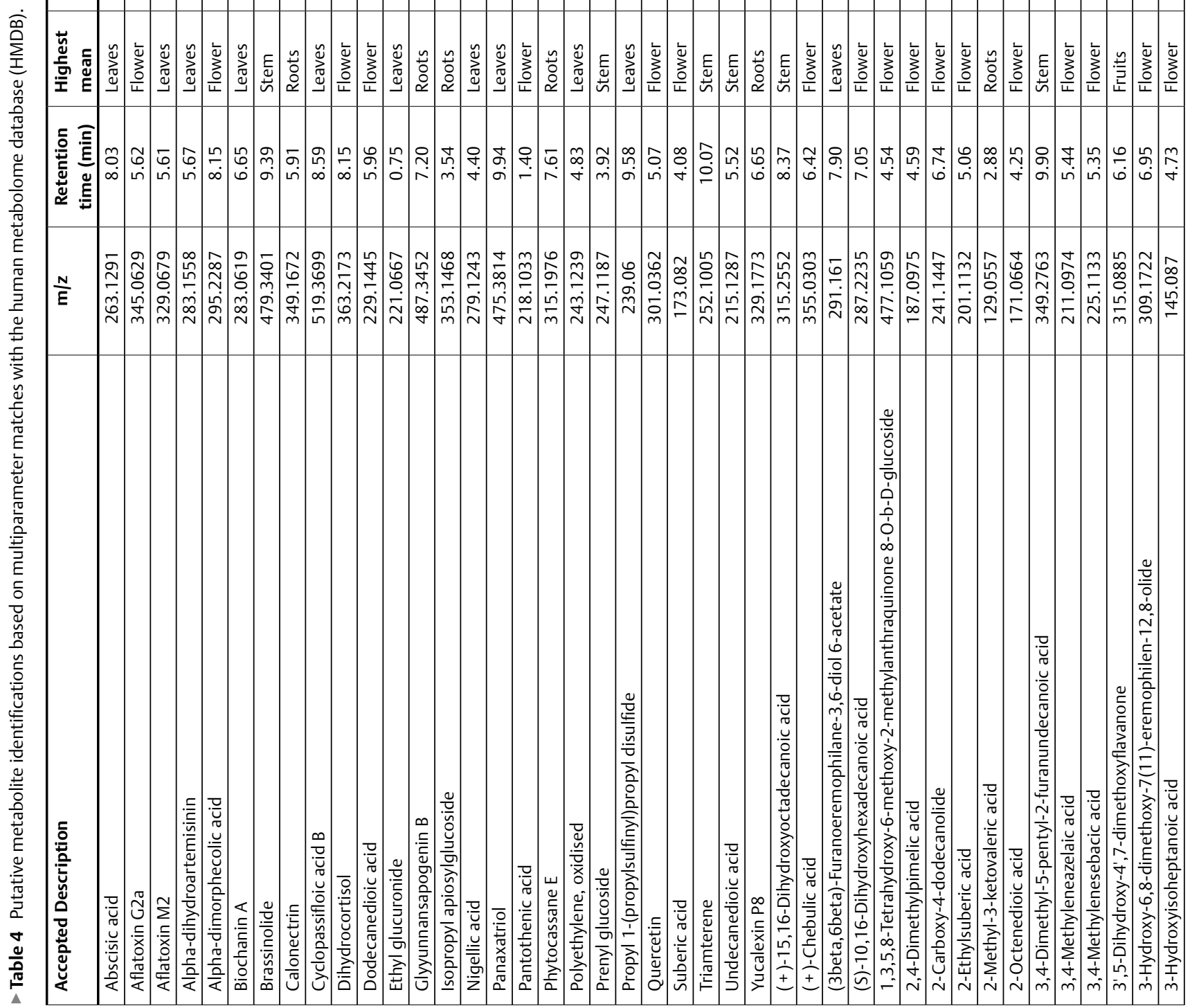




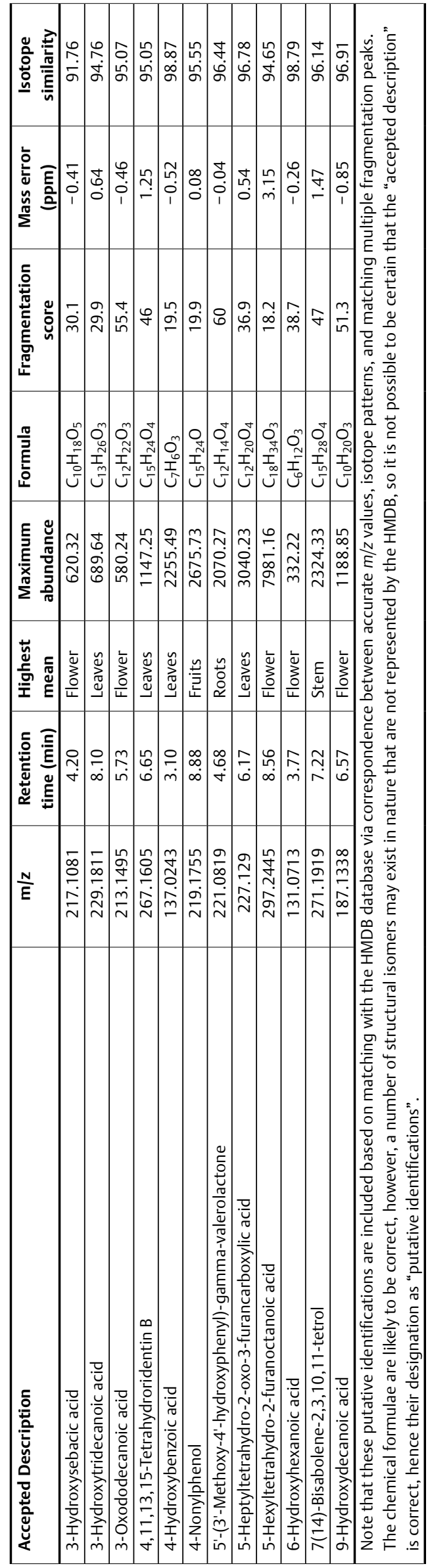

\section{Materials and Methods}

\section{Chemicals and reagents}

All HPLC-grade solvents (methanol, ethanol, acetonitrile, formic acid, and polyphenolic standards) were purchased from Sigma-Aldrich.

\section{Plant material}

Aerial parts (leaves, stems, fruits, flowers) and roots of M. annua were collected from plants growing at Quaid-i-Azam University, Islamabad campus, between September and October 2015. Plant authentication was performed by plant taxonomist Prof. Dr. Mir Ajab Khan, Department of Plant Sciences, Quaid-i-Azam University, Islamabad, and a voucher specimen (no. 308) was deposited in a herbarium of the same department. Plant samples were air/ shade-dried at room temperature, then chopped and ground into fine powder and stored in an air-tight container prior to extraction.

\section{Extraction protocols}

\section{Maceration}

$100 \mathrm{mg}$ of each dried plant part (leaves, stems, fruits, flowers, and roots) were placed in separate $1.5 \mathrm{~mL}$ Eppendorf tubes and $1 \mathrm{~mL}$ of methanol was added to each. The mixture was kept at room temperature overnight. The mixture was then centrifuged at $10000 \mathrm{rpm}$ for $15 \mathrm{~min}$ and the resulting supernatant was filtered through a $0.45-\mu \mathrm{M}$. nylon syringe filter (Thermo Fisher Scientific). The extraction was repeated in triplicate. The extracted stock solutions were then diluted further with methanol ( $10 \mathrm{uL}$ stock solution to $1000 \mathrm{uL} \mathrm{MeOH}$ ) in preparation for LC-MS. Each sample was frozen and stored at $-20^{\circ} \mathrm{C}$ until the day of analysis.

\section{Ultrasonication}

Dried plant parts (100 mg each of leaves, stems, fruits, flowers, and roots) were added separately to methanol $(1 \mathrm{~mL})$ in a 1.5 -mL Eppendorf tube and kept in an ultrasonic bath for $15 \mathrm{~min}$. The mixture was then centrifuged at $10000 \mathrm{rpm}$ for $15 \mathrm{~min}$, and the resulting supernatant was filtered through a $0.45-\mu \mathrm{M}$ nylon syringe filter (Thermo Fisher Scientific). The extraction was repeated in triplicate. These extracts were then diluted further with methanol (10 uL stock solution to $1000 \mathrm{uL}$ $\mathrm{MeOH}$ ) in preparation for LC-MS/MS. Each sample was frozen and stored at $-20^{\circ} \mathrm{C}$ until the day of analysis.

\section{Homogenisation}

Dried plant parts (100 mg each of leaves, stems, fruits, flowers, and roots) were added to separate $15 \mathrm{~mL}$ Precellys homogeniser vials with ceramic beads (zirconium dioxide) and $1 \mathrm{~mL}$ of methanol was added to each. Homogenisation took place for $1 \mathrm{~min}$ at $50000 \mathrm{rpm}$ with a pause time of $25 \mathrm{~s}$ (Precellys Evolution154 homogeniser; Bertin Instrument). The mixture was then centrifuged at 10000 rpm for $15 \mathrm{~min}$, and the resulting supernatant was filtered through a $0.45-\mu \mathrm{M}$ nylon syringe filter (Thermo Fisher Scientific). The extraction was repeated in triplicate. The extracts were then diluted further with methanol $(10 \mu \mathrm{L}$ stock solution to $1000 \mu \mathrm{L} \mathrm{MeOH})$ in preparation for LC-MS/MS. Each sample was frozen and stored at $-20^{\circ} \mathrm{C}$ until the day of analysis. 
- Table 5 Known biological and medicinal activity of identified compounds.

\begin{tabular}{|c|c|c|c|c|}
\hline No & Compound ID & Type of compound & Biological/medicinal effect & $\begin{array}{l}\text { References for medicinal/ } \\
\text { biological activity }\end{array}$ \\
\hline 1 & Protocatechuic acid & Phenolic acid & $\begin{array}{l}\text { Cytotoxic, chemopreventive, apoptotic, and neuroprotective } \\
\text { activity }\end{array}$ & {$[28-30]$} \\
\hline 2 & Gentisic acid & Phenolic acid & Anti-inflammatory, antirheumatic, and cytostatic properties & [31] \\
\hline 3 & Caffeic acid & Phenolic acid & Antimicrobial and anticancer activity & {$[32-33]$} \\
\hline 4 & Syringic acid & Phenolic acid & Antioxidant, antibacterial, and hepatoprotective activity & {$[34-35]$} \\
\hline 5 & Rutin & Flavonol glycoside & Antioxidant, antihyperglycaemic, and anticancer activity & {$[36-38]$} \\
\hline 6 & Homovanilic acid & Phenolic acid & $\begin{array}{l}\text { Hepatoprotective and a novel specific inhibitor of snake venom } \\
5 \text { '-nucleotidase }\end{array}$ & {$[34,39]$} \\
\hline 7 & p-Coumaric acid & Phenolic acid & Antioxidant, antitumour, and antimicrobial activity & {$[40-42]$} \\
\hline 8 & Sinapic acid & Phenolic acid & Antioxidant and antiproliferative activity & {$[43-44]$} \\
\hline 9 & trans-Ferulic acid & Phenolic acid & Antioxidant, antiproliferative, and apoptotic properties & {$[45-46]$} \\
\hline 10 & Salicylic acid & Phenolic acid & $\begin{array}{l}\text { Analgesic, antipyretic, anti-inflammatory, antiseptic, and antifungal } \\
\text { properties }\end{array}$ & {$[46]$} \\
\hline 11 & Luteolin & Flavone & $\begin{array}{l}\text { Antioxidant, anticancer, antileishmanial, and anti-inflammatory } \\
\text { activity }\end{array}$ & {$[47-50]$} \\
\hline 12 & Apigenin & Flavone & Antibacterial and antileukaemic activity & {$[51-52]$} \\
\hline 13 & Kaempferol & Flavonol & Anticancer activity & {$[53-55]$} \\
\hline 14 & Hispidulin & Flavone & Anticancer activity & [68] \\
\hline 15 & Hesperetin & Flavanone & Anticancer, antioxidant, and neuroprotective activity & {$[56-58,68]$} \\
\hline 16 & Isorhamnetin & Flavonol & Anti-inflammatory activity & [59] \\
\hline
\end{tabular}

\section{Authentic standard sample preparation}

Stock solutions of each metabolite standard were prepared by mixing 8 compounds together in methanol:milli-Q water (50:50\%) at a concentration of $1 \mathrm{mg} / \mathrm{mL}$. All standard solutions were further diluted to $10 \mu \mathrm{g} / \mathrm{mL}$ with methanol in preparation for LC-MS/MS analysis.

\section{LC-MS}

Compounds were identified in plant extracts using a Thermo Scientific Ultimate 3000 liquid chromatography system coupled directly to a Q-Exactive HF Hybrid Quadrupole-Orbitrap mass spectrometer with a HESI Il electrospray ionisation source (Thermo Scientific). A $10 \mu \mathrm{L}$ partial loop injection was used for all analyses and the chromatographic separation was performed using a Waters Acquity UPLC HSST3 column $(2.1 \times 100 \mathrm{~mm}$ and $1.8 \mu \mathrm{M}$ particle size). The mobile phase flow rate was $0.4 \mathrm{~mL} / \mathrm{min}$. The total run time was 12 min and the mobile phase composition was as follows: mobile phase A: $0.1 \%$ aqueous formic acid and mobile phase B: HPLC grade acetonitrile. A linear elution gradient was used as follows: 0 min, $1 \%$ B; 1 min, $1 \%$ B; 8 min, $95 \%$ B; 9 min, $95 \%$ B; 9.1 min, $1 \%$ $B ; 12 \mathrm{~min}, 1 \% \mathrm{~B}$. Analysis was performed in the negative ion mode using a scan range from $\mathrm{m} / \mathrm{z} 60-900 \mathrm{Da}$ and the resolution was set to 70000. The tune file source parameters were set as follows: sheath gas flow 60; aux gas flow 20; spray voltage $3.6 \mathrm{kV}$; capillary temperature $320^{\circ} \mathrm{C}$; S-lens RF value 70 ; heater temperature $300^{\circ} \mathrm{C}$. The AGC target was set to $1 \mathrm{e}^{6}$ and the Max IT value was $250 \mathrm{~ms}$. The column temperature was kept at $30^{\circ} \mathrm{C}$ throughout the experiment. Peaks retention times were identified from the injection of authentic standards at a $10 \mu \mathrm{g} / \mathrm{mL}$ concentration in Milli-Q water, and metabolite identification was performed using a combination of accurate mass analysis ( $<5 \mathrm{ppm}$ ), retention time $<0.1 \mathrm{~min}, \mathrm{MS} /$ MS peak matching, and isotope pattern matching. Data processing and identification of metabolites were made using Thermo Scientific Xcaliber (Thermo Fisher Scientific) and Waters Progenesis QI.

\section{Tandem mass spectrometry}

The full scan data was combined with data-directed $\mathrm{MS}^{2}$ scanning to provide fragmentation spectra for selected peaks at 17500 resolution. The MS/MS settings were as follows: AGC $1 \mathrm{e}^{5}$, Max IT $50 \mathrm{~ms}$, loop count 5 , isolation window $1.0 \mathrm{~m} / \mathrm{z}$, NCE 30, intensity threshold $2 \mathrm{e}^{4}$.

\section{Data processing}

Raw data were processed using Progenesis QI for small molecules (Waters) and Xcaliber Qualbrowser and Quanbrowser (Thermo Fisher Scientific). Untargeted profiling incorporated chromatographic peak alignment, isotope cluster recognition (peak picking), and compound identification. Identification was based on matching experimental measurements for each compound to values obtained from an in-house library of authentic standards. 4 orthogonal measurements were compared for each compound. These were accurate mass measurement ( $<5 \mathrm{ppm}$ ) based on a theoretical mass derived from the chemical formula, experimental retention time matching (window of $0.1 \mathrm{~min}$ ), >90\% isotope pattern recognition (calculated from the chemical formula), and matching fragmentation patterns from an authentic standard, which were available from survey scans. All values in the database were obtained from the analysis of authentic standard compounds. 


\section{Quality control samples}

Quality control (QC) samples were analysed to monitor reproducibility, precision, variability, and bias of LC-MS data. The $5 \mu \mathrm{L}(10 \mu \mathrm{g} / \mathrm{mL})$ $\mathrm{QC}$ samples comprised $5 \mu \mathrm{L}$ of each sample added together in a single vial and injected 10 times at the start of the sample sequence and 6 times at the end.

\section{Precision}

Typical analytical precision was characterised via 3 replicate measurements of the standard. The result is expressed as a relative standard deviation (\%RSD), see > Table 1S, Supporting Information.

\section{Limit of detection and limit of quantification}

The LOD was determined based on a signal-to-noise ratio of approximately 3:1 for the analyte compared to baseline noise. The LODs were in the range of $4.2 \mathrm{pg} / \mathrm{mL}$ and $13.3 \mathrm{ng} / \mathrm{mL}$ for the identified compounds for which authentic standards were available. LOQs were determined by creating a separate calibration curve for each compound and identifying the lowest concentration in the linear range of the curve that had a signal-to-noise ration of at least $10: 1$. The LOQ values were in the range of $12.8 \mathrm{pg} / \mathrm{mL}$ and $200 \mathrm{ng} /$ $\mathrm{mL}$ for the identified compounds for which authentic standards were available. A table of LOD and LOQ values for each compound identified with authentic standards can be found in > Table 1S, Supporting Information. - Fig. 1S, Supporting Information, provides the calibration curve for trans-ferulic acid. Calibration curves were created for each metabolite identified.

\section{Supporting information}

The LOD and LOQ, a heat map showing the average concentration of each 'level 1' identified metabolite, the calibration curve for trans-ferulic acid, and detailed data on the identification of compounds 17-34 are available as Supporting Information.

\section{Acknowledgments}

We would like to acknowledge the Higher Education Commission of Pakistan for financial support under the "International Research Support Initiative Program" and Dr. James Wickens from the Department of Chemistry, University of Oxford, for technical support.

\section{Conflict of Interest}

No conflict of interest has been declared by the author(s).

\section{References}

[1] Flora G, Josephine MM, Chandra M, Nanthini M, Shalini K, Shantha P, Sivam AR, Valli S. Study on antioxidant potential of different parts of Martynia annua Linn. - a road side weed. Int J Dev Res 2013; 3: 051-054

[2] Nagda D, Saluja A, Nagda C. Antioxidant activities of methanolic and aqueous extract from leaves of Martynia annua Linn. Pharmacogn J 2009; 1: 288-297

[3] Dhingra AK, Chopra B, Mittal SK. Martynia annua L.: A review on its ethnobotany, phytochemical and pharmacological profile. J Pharmacogn Phytochem 2013; 1: 135-140
[4] Babu HB, Mohana LS, Saravana AK. Studies on phytochemical and anticonvulsant property of Martynia annua Linn. Int J Phytopharmacol 2010; 1: 82-86

[5] Satyavati GV, Gupta AK, Tandon N. Medicinal plants of India. Vol. II. Indian Council of Medical Research: New Delhi. 1987: 223-229

[6] Watt G. Dictionary of the economic products of India. Vol. V, Cosmo Publications; New Delhi. 1972: 676

[7] Pillai TSK, Thampi PP, Verma KC. Preliminary pharmacognostioc study of Martynia diandiae Glox. Madhya Bharti J 1964: 29: 11-13

[8] Parvati A, Narayana IL. Chemotaxonomy of a few taxa of Pedaliaceae. Curr Sci 1978; 47: 282

[9] Frei B, Higdon JV. Antioxidant activity of tea polyphenols in vivo: Evidence from animal studies. J Nutr 2003; 133: 3275S-3284S

[10] French K, Harvey J, McCullagh JSO. Targeted and untargeted metabolic profiling of wild grassland plants identifies antibiotic and anthelmintic compounds targeting pathogen physiology, metabolism and reproduction. Sci Rep 2018; 8: 1695

[11] Pandey KB, Rizvi SI. Plant polyphenols as dietary antioxidants in human health and disease. Oxid Med Cell Longev 2009; 2: 270-278

[12] Scholz S, Williamson G. Interactions affecting the bioavailability of dietary polyphenols in vivo. Int J Vitam Nutr Res 2007; 77: 224-235

[13] Shen Y, Zhang H, Cheng L, Wang L, Qian H, Qi X. In vitro and in vivo antioxidant activity of polyphenols extracted from black highland barley. Food Chem 2016; 194: 1003-1012

[14] Guo Q, Zhao L, You Q, Yang Y, Gu H, Song G, Lu N, Xin J. Anti-hepatitis $B$ virus activity of wogonin in vitro and in vivo. Antiviral Res 2007; 74 : $16-24$

[15] Cãrdenas M, Marder M, Blank VC, Roguin LP. Antitumor activity of some natural flavonoids and synthetic derivatives on various human and murine cancer cell lines. Bioorg Med Chem 2006; 14: 2966-2971

[16] Hong JW, Yang GE, Kim YB, Eom SH, Lew JH, Kang H. Anti-inflammatory activity of cinnamon water extracts in vivo and in vitro LPS-induced models. BMC Complement Altern Med 2012; 12: 237

[17] Mondal A, Maity TK, Pal D, Sannigrahi S, Singh J. Isolation and in vivo hepatoprotective activity of Melothria heterophylla (Lour.) Cogn. against chemically induced liver injuries in rats. Asian Pac J Trop Med 2011; 4: 619-623

[18] Tijburg LB, Mattern T, Folts JD, Weisgerber UM, Katan MB. Tea flavonoids and cardiovascular disease: a review. Crit Rev Food Sci Nutr 1997; 37: 771-785

[19] Want E], Masson P, Michopoulos F, Wilson ID, Theodoridis G, Plumb RS, Shockcor J, Loftus N, Holmes E, Nicholson JK. Global metabolic profiling of animal and human tissues via UPLC-MS. Nat Protoc 2013; 8: 17-32

[20] Sumner LW, Amberg A, Barrett D, Beale MH, Beger R, Daykin CA, Fan TWM, Fiehn O, Goodacre R, Griffin LJ, Hankemeier T, Hardy N, Harnly J, Higashi R, Kopka J, Lane AN, Lindon AC, Marriott P, Nicholls AW, Reily MD, Thaden J], Viant MR. Proposed minimum reporting standards for chemical analysis chemical analysis working group (CAWG) metabolomics standards initiative (MSI). Metabolomics 2007; 3: 211-221

[21] Dunn WB, Alexander E, Ralf JM, Weber Darren J, Creek Marie B, Rainer B, Thomas H, Royston G, Steffen N, Joachim K, Mark RV. Mass appeal: Metabolite identification in mass spectrometry-focused untargeted metabolomics. Metabolomics 2013; 9: 44-66

[22] Grayer RJ, Kite GC, Abou-Zaid M, Archer L]. The application of atmospheric pressure chemical ionisation liquid chromatography-mass spectrometry in the chemotaxonomic study of flavonoids: Characterisation of flavonoids from ocimum gratissimum var. gratissimum. Phytochem Anal 2000; 11: 257-267

[23] Sánchez-Rabaneda F, Jáuregui O, Casals I, Andrés-Lacueva C, Izquierdo-Pulido M, Lamuela-Raventós RM. Liquid chromatographic/ electrospray ionization tandem mass spectrometric study of the phenolic composition of cocoa (theobroma cacao). J Mass Spectrom 2003; 38: 35-42 
[24] March RE, Lewars EG, Stadey CG, Miao XS, Zhao X, Metcalfe CD. A comparison of flavonoid glycosides by electrospray tandem mass spectrometry. J Mass Spectrom 2006; 248: 61-85

[25] Benayad Z, Gómez-Cordovés C, Es-Safi NE. Characterization of flavonoid glycosides from fenugreek (Trigonella foenum-graecum) crude seeds by HPLC-DAD-ESI/MS analysis. Int J Mol Sci 2014; 15: 20668-20685

[26] Iwashina T. The structure and distribution of the flavonoids in plants. J Plant Res 2000; 113: 287-299

[27] Markham KR. Techniques of flavonoid identification. New York: Academic Press; 1982: 36-51

[28] Yip ECH, Chan ASL, Pang H, Tam YK, Wong YH. Protocatechuic acid induces cell death in HepG2 hepatocellular carcinoma cells through a c-Jun N-terminal kinase-dependent mechanism. Cell Biol Toxicol 2006; 22: 293-302

[29] Yin MC, Lin CC, Wu HC, Tsao SM, Hsu CK. Apoptotic effects of protocatechuic acid in human breast, lung, liver, cervix, and prostate cancer cells: Potential mechanisms of action. J Agric Food Chem 2009; 57: 6468-6473

[30] An LJ, Guan S, Shi GF, Bao YM, Duan YL, Jiang B. Protocatechuic acid from alpinia oxyphylla against MPP +-induced neurotoxicity in PC12 cells. Food Chem Toxicol 2006; 44: 436-443

[31] Ashidate K, Kawamura M, Mimura D, Tohda H, Miyazaki S, Teramoto T, Yamamoto Y, Hirata Y. Gentisic acid, an aspirin metabolite, inhibits oxidation of low-density lipoprotein and the formation of cholesterol ester hydroperoxides in human plasma. Eur J Pharmacol 2005; 513: 173-179

[32] Alves M], Ferreira ICFR, Froufe HJC, Abreu RMV, Martins A, Pintado M. Antimicrobial activity of phenolic compounds identified in wild mushrooms, SAR analysis, and docking studies. J Appl Microbiol 2013; 115: 346-357

[33] Hwang HJ, Park H], Chung HJ, Min HY, Park E], Hong JY, Lee SK. Inhibitory effects of caffeic acid phenethyl ester on cancer cell metastasis mediated by the down-regulation of matrix metalloproteinase expression in human HT1080 fibrosarcoma cells. J Nutr Biochem 2006; 17: 356-362

[34] Itoh A, Isoda K, Kondoh M, Kawase M, Watari A, Kobayashi M, Tamesada M, Yagi K. Hepatoprotective effect of syringic acid and vanillic acid on CCl4-induced liver injury. Biol Pharm Bull 2010; 33: 983-987

[35] Kong WK, Zhao YL, Shan LM, Xiao XH, Guo WY. Thermochemical studies on the quantity-antibacterial effect relationship of four organic acids from Radix isatidis on Escherichia coli growth. Biol Pharm Bull 2008; 31: 1301-1305

[36] Zielińska D, Szawara-Nowak D, Zieliński H. Determination of the antioxidant activity of rutin and its contribution to the antioxidant capacity of diversified buckwheat origin material by updated analytical strategies. Pol J Food Nutr Sci 2010; 60: 315-321

[37] Kamalakkannan N, Prince PS. Antihyperglycaemic and antioxidant effect of rutin, a polyphenolic flavonoid, in streptozotocin-induced diabetic wistar rats. Basic Clin Pharmacol Toxicol 2006; 98: 97-103

[38] Dixit S. Anticancer effect of rutin isolated from the methanolic extract of triticum aestivum straw in mice. Med Sci 2014; 2: 153-160

[39] Dhananjaya BL, Nataraju A, Gowda CDR, Sharath BK, D'Souza CJM. Vanillic acid as a novel specific inhibitor of snake venom 5'-nucleotidase: A pharmacological tool in evaluating the role of the enzyme in snake envenomation. Biochemistry (Mosc) 2009; 74: 1315-1319

[40] Rice-Evans CA, Miller N], Paganga G. Structure-antioxidant activity relationships of flavonoids and phenolic acids. Free Radic Biol Med 1996; 20: 933-956

[41] Heleno SA, Ferreira ICFR, Calhelha RC, Esteves AP, Queiroz MJRP. Cytotoxicity of coprinopsis atramentaria extract, organic acids and their synthesized methylated and glucuronate derivatives. Food Res Int 2014; 55: 170-175
[42] Heleno SA, Ferreira ICFR, Ćirić A, Glamočlija J, Martins A, Queiroz MJRP, Soković M. Coreopsis atramentaria extract, organic acids, 25 synthesized glucuronated and methylated derivatives as antibacterial and antifungal agents. Food Funct 2014; 5: 2521-2528

[43] Galano A, Francisco-Marquez M, Alvarez-Idaboy JR. Mechanism and kinetics studies on the antioxidant activity of Sinapinic acid. Phys Chem Chem Phys 2011; 13: 11199-11205

[44] Kampa M, Alexaki VI, Notas G, Nifli AP, Nistikaki A, Hatzoglou A, Bakogeorgou E, Kouimtzoglou E, Blekas G, Boskou D, Gravanis A, Castanas E. Antiproliferative and apoptotic effects of selective phenolic acids on T47D human breast cancer cells: Potential mechanisms of action. Breast Cancer Res 2004; 6: R63-R74

[45] Kikuzaki H, Hisamoto M, Hirose K, Akiyama K, Taniguchi H. Antioxidant properties of ferulic acid and its related compounds. J Agric Food Chem 2002; 50: 2161-2168

[46] Lin AN, Nakatsui T. Salicylic acid revisited. Int J Dermat 1998; 37 : 335-342

[47] Brown JE, Rice-Evans CA. Luteolin-rich artichoke extract protects low density lipoprotein from oxidation in vitro. Free Radic Res 1998; 29: 247-255

[48] Fang J, Zhou Q, Shi XL, Jiang BH. Luteolin inhibits insulin-like growth factor 1 receptor signaling in prostate cancer cells. Carcinogenesis 2007; 28: 713-723

[49] Mittra B, Saha A, Chowdhury AR, Pal C, Mandal S, Mukhopadhyay S, Bandyopadhyay S, Majumder HK. Luteolin, an abundant dietary component is a potent anti-leishmanial agent that acts by inducing topoisomerase II-mediated kinetoplast DNA cleavage leading to apoptosis. Mol Med 2000; 6: 527-541

[50] Ziyan L, Yongmei Z, Nan Z, Ning T, Baolin L. Evaluation of the anti-inflammatory activity of luteolin in experimental animal models. Planta Med 2007; 73: 221-226

[51] Nayaka HB, Londonkar RL, Umesh MK, Tukappa A. Antibacterial attributes of apigenin, isolated from portulaca oleracea L. Int J Bacteriol 2014; 2014: 175851

[52] Budhraja A, Gao N, Zhang Z, Son YO, Cheng S, Wang X, Ding S, Hitron A, Chen G, Luo J, Shi X. Apigenin induces apoptosis in human leukemia cells and exhibits anti-leukemic activity in vivo. Mol Cancer Ther 2012; 11: $132-142$

[53] Luo H, Rankin GO, Liu L, Daddysman MK, Jiang BH, Chen YC. Kaempferol inhibits angiogenesis and VEGF expression through both HIF dependent and independent pathways in human ovarian cancer cells. Nutr Cancer 2009; 61: 554-563

[54] Damianaki A, Bakogeorgou E, Kampa M, Notas G, Hatzoglou A, Panagiotou S, Gemetzi C, Kouroumalis E, Martin PM, Castanas E. Potent inhibitory action of red wine polyphenols on human breast cancer cells. J Cell Biochem 2000; 78: 429-441

[55] Kim B, Choi YE, Kim HS. Eruca sativa and its flavonoid components, quercetin and isorhamnetin, improve skin barrier function by activation of peroxisome proliferator activated receptor (PPAR)- $\alpha$ and suppression of inflammatory cytokines. Phytother Res 2014; 28 : 1359-1366

[56] Shirzad M, Pezhman B, Esfandiar H. The effects of hesperetin on apoptosis induction and inhibition of cell proliferation in the prostate cancer PC3 cells. J Herbmed Pharmacol 2015; 4: 121-124

[57] Roohbakhsh A, Parhiz H, Soltani F, Rezaee R, Iranshahi M. Molecular mechanisms behind the biological effects of hesperidin and hesperetin for the prevention of cancer and cardiovascular diseases. Life Sci 2015; 124: $64-74$

[58] Cho J. Antioxidant and neuroprotective effects of hesperidin and its aglycone hesperetin. Arch Pharm Res 2006; 29: 699-706 
[59] Hamalainen M, Nieminen R, Vuorela P, Heinonen M, Moilanen E. Anti-inflammatory effects of flavonoids: genistein, kaempferol, quercetin, and daidzein inhibit STAT-1 and NF-KB activations, whereas flavone, isorhamnetin, naringenin, and pelargonidin inhibit only NF-KB activation along with their inhibitory effect on iNOS expression and NO production in activated macrophages. Mediators Inflamm 2007; 2007: 45673

[60] Lee YS. Role of NADPH oxidase-mediated generation of reactive oxygen species in the mechanism of apoptosis induced by phenolic acids in HepG2 human hepatoma cells. Arch Pharm Res 2005; 28: 1183-1189

[61] Kim SH, Choi KC. Anti-cancer effect and underlying mechanism(s) of kaempferol, a phytoestrogen, on the regulation of apoptosis in diverse cancer cell models. Toxocol Res 2013; 29: 229-234

[62] Antunes-Ricardo M, Gutiérrez-Uribe JA, Martínez-Vitela C, Serna-Saldívar SO. Topical anti-inflammatory effects of isorhamnetin glycosides isolated from Opuntia ficus-indica. Biomed Res Int 2015; 2015: 847320

[63] Xu SL, Choi RC, Zhu KY, Leung KW, Guo A], Bi D, Xu H, Lau DT, Dong TT, Tsim KW. Isorhamnetin, a flavonol aglycone from Ginkgo biloba L., induces neuronal differentiation of cultured PC12 cells: Potentiating the effect of nerve growth facto. r. Evid Based Complement Alternat Med 2012; 2012: 278273
[64] Viola H, Wasowski C, Levi De Stein M, Wolfman C, Silveira R, Dajas F, Medina JH, Paladini AC. Apigenin a component of matricaria recutita flowers, is a central benzodiazepine receptors-ligand with anxiolytic effects. Planta Med 1995; 61: 213-216

[65] Jacobson KA, Moro S, Manthey JA, West PL, Ji XD. Interactions of flavones and other phytochemicals with adenosine receptors. Adv Exp Med Biol 2002; 505: 163-171

[66] Losi G, Puia G, Garzon G, de Vuono MC, Baraldi M. Apigenin modulates GABAergic and glutamatergic transmission in cultured cortical neurons. Eur J Pharm 2004; 502: 41-46

[67] Katavic PL, Lamb K, Navarro H, Prisinzano TE. Flavonoids as opioid receptor ligands: Identification and preliminary structure-activity relationships. J Nat Prod 2007; 70: 1278-1282

[68] Kavvadias D, Sand P, Youdim KA, Qaiser MZ, Rice-Evans C, Baur R, Sigel E, Rausch WD, Riederer P, Schreier P. The flavone hispidulin, a benzodiazepine receptor ligand with positive allosteric properties, traverses the blood-brain barrier and exhibits anticonvulsive effects. Brit J Pharmacol 2004; 142: 811-820 